\title{
Análise do desempenho ambiental das usinas sucroenergéticas localizadas na Bacia Hidrográfica do Rio Mogi Guaçu
}

\author{
Analysis of the environmental performance of the sugar energy plants \\ located in the Hydrographic Basin of the River Mogi Guaçu
}

Marcelo Girotto Rebelato', Leonardo Lucas Madaleno², Andréia Marize Rodrigues

$\square$

\begin{abstract}
RESUMO
Este artigo teve como objetivo analisar o desempenho ambiental das usinas sucroenergéticas pertencentes à Bacia do Rio Mogi Guaçu. Com a identificação dos resíduos e subprodutos gerados em cada etapa do processo produtivo do açúcar e do etanol, identificaramse seus impactos potenciais e realizouse, por meio do método Analytic Hierarchy Process (AHP), uma ponderação quantitativa do impacto ambiental relativo de cada resíduo/subproduto considerando o despejo desses poluentes nas águas, no solo e na atmosfera. A partir disso, avaliaramse, por intermédio de pesquisa em campo, as usinas da bacia com base na destinação dada a 27 diferentes resíduos/subprodutos. Concluise que produção industrial sucroenergética apresentou maior impacto ambiental relativo nas águas (67,4\%), seguida por solo (22,6\%) e atmosfera (10,07\%). Com base nos conhecimentos científicos atestados até o presente momento sobre os impactos ambientais de cada despejo, também foi possível concluir que as destinações dos resíduos/ subprodutos das usinas são, em média, 95\% adequadas.
\end{abstract}

Palavraschave: avaliação do desempenho ambiental; usinas sucroenergéticas; Bacia Hidrográfica do Rio Mogi Guaçu.

\begin{abstract}
This article aims to analyze the environmental performance of the plants belonging to sugar energy plants of the River Mogi Guaçu Basin. With the identification of waste and byproducts generated at each stage of sugar and ethanol production process, were identified the potential impacts and carried out a quantitative estimation of the relative environmental impact of each waste/byproduct considering the dumping of these pollutants in water, soil and atmosphere. From this, it was evaluated through field research, the plants of the basin based on the destination given to twentyseven different waste/ byproducts. It was concluded that industrial sugar energy production presents greater environmental impact on waters (67.4\%), followed by sand (22.6\%) and air (10.7\%). Based on scientific knowledge attested to date on the environmental impacts of each dump, also was concluded that the allocations of waste/byproducts of plants are on average 95\% adequate.
\end{abstract}

Keywords: environmental performance evaluation; sugar energy plants; River Mogi Guaçu Hydrographic Basin.

\section{INTRODUÇÃO}

A agroindústria sucroenergética, apesar de toda tradição e da importância na economia nacional, tem sido alvo de inquietações e julgamentos críticos relativamente aos impactos ambientais negativos que seus processos industriais produzem no meio ambiente (PIACENTE, 2005; MACHADO \& SILVA, 2010). O processamento industrial da canadeaçúcar apresenta uma cadeia produtiva em que várias de suas etapas, se não gerenciadas adequadamente, podem provocar impactos ambientais indesejados principalmente associados ao solo e à água (ANA, 2009).
Além da utilização intensiva da água como insumo produtivo, a produção do etanol e do açúcar é geradora de resíduos como a vinhaça, o bagaço, a torta de filtro, a flegmaça, efluentes da lavagem de pisos e equipamentos, entre outros, os quais podem causar impactos significativos ao meio ambiente. Em bacias hidrográficas com menor disponibilidade de água, pode ser também um competidor expressivo pelos recursos hídricos, com destaque nas regiões em que a canadeaçúcar necessita de irrigação plena (ANA, 2009).

'Doutor. Professor Assistente da Universidade Estadual Paulista “Júlio de Mesquita Filho” (UNESP) - Jaboticabal (SP), Brasil.

${ }^{2}$ Doutor. Professor Assistente da Faculdade de Tecnologia (FATEC) - Jaboticabal (SP), Brasil.

Endereço para correspondência: Marcelo Girotto Rebelato - Via de Acesso Prof. Paulo Donato Castellane, s/n - Zona Rural - 14884-900 - Jaboticabal (SP), Brasil -

Email: mgiroto@fcav.unesp.br

Recebido: 18/11/13 - Aceito: 27/01/16 - Reg. ABES: 126712 
Observase que, mesmo já sendo regido por um grande conjunto de leis com vistas à regulação de suas atividades visando à prevenção e à minimização dos impactos ambientais de suas operações (OLIVEIRA et al., 2009), o setor vem constantemente apresentando posturas mais modernas na gestão das suas atividades industriais a partir da adoção de ações e contramedidas que visam mitigar os efeitos prejudiciais dos resíduos e subprodutos ao meio ambiente (MACHADO \& SILVA, 2010).

A busca por objetivos produtivos alinhados às questões ambientais está não somente ligada à necessidade de desenvolvimento de indicadores de desempenho ambiental que possam apontar os impactos ambientais das operações industriais. Está também associada à avaliação e ao diagnóstico da atuação ambiental das empresas com vistas à melhoria desse desempenho (ROHRICH \& CUNHA, 2004). Nesse contexto, a Bacia Hidrográfica do Rio Mogi Guaçu (BHMG) surge como unidade de estudo de interesse em função de três aspectos (RODRIGUES, 2004):

1. de ser a bacia onde se concentra a maior parte da atividade canavieira do Brasil;

2. da fragmentação florestal observada, estando alguns municípios com menos de $1 \%$ da sua vegetação nativa;

3. da heterogeneidade econômica das usinas, abrigando a referida bacia empresas com ótimo desempenho econômico e outras com sérios problemas.

A partir do exposto, este trabalho teve como objetivo apresentar uma avaliação do desempenho ambiental das operações industriais das usinas sucroenergéticas localizadas na BHMG. Ressaltase que não constituiu objetivo do artigo abarcar os resíduos e subprodutos das etapas realizadas na área agrícola, quais sejam, plantação, cultivo, corte e carregamento da canadeaçúcar. O trabalho foi relevante na medida em que contribui com a reflexão sobre a sustentabilidade no setor sucroenergético, com o desenvolvimento de indicadores mais eficazes aplicados à avaliação dos impactos ambientais provocados pelas empresas do setor e como subsídio para desenvolvimento de metodologias de gestão ambiental que contribuam para minoração do passivo ambiental de suas atividades industriais.

\section{METODOLOGIA}

Atualmente, muitos pesquisadores argumentam que o estudo de questões ambientais seja feito a partir dos recortes definidos pelas bacias hidrográficas. Isso porque a qualidade ambiental de uma determinada região associase às formas de ocupação e uso de seus recursos naturais, com destaque aos recursos hídricos superficiais e subterrâneos. Tratase de um recorte territorial adequado ao estudo da produção sucroenergética sob o enfoque ambiental, dado tratarse de uma indústria geradora de resíduos e subprodutos que tem nas águas seu maior impacto. Além disso, a legislação ambiental brasileira também recomenda a adoção da bacia hidrográfica como um recorte adequado para avaliação de impactos ambientais (MILARÉ, 2000).

A BHMG (Figura 1) compreende uma área total de $17.460 \mathrm{~km}^{2}$, com $14.653 \mathrm{~km}^{2}$ localizados no Estado de São Paulo (STORANI \& PEREZ FILHO, 2009). Neste, a BHMG está situada em uma das regiões mais industrializadas e é considerada uma importante bacia, uma vez que engloba 59 municípios, sendo que 38 deles possuem suas sedes nessa bacia, totalizando uma área de $13.061 \mathrm{~km}^{2}$, com um total de 1.293.474 habitantes (SIGRH, 2012). Além disso, merece destaque a cultura de canadeaçúcar, com produção de 346.293 .389 t na safra 2008/2009. Dessa maneira, tanto em relação ao cenário socioeconômico quanto à questão ambiental, é destacada a importância do setor sucroenergético para a BHMG (UNICA, 2012; SÃO PAULO, 2008). Os autores constataram, por meio da pesquisa em campo, que das 28 usinas em funcionamento em 2004, atualmente observase um total de 25 usinas sucroenergéticas em operação.

A metodologia utilizada neste trabalho foi composta de seis etapas, a saber:

1. mapeamento das etapas produtivas da produção sucroenergética - nesta etapa foram realizados a identificação e o estudo das operações unitárias de transformação do caldo extraído da cana em açúcar, em etanol e nos resíduos/subprodutos do processo industrial;

2. identificação e estudo dos resíduos/subprodutos gerados - nesta etapa construiuse um inventário dos resíduos/subprodutos gerados pelas operações de fabricação do açúcar e do etanol, identificando suas características, composição, legislação aplicável e destinações possíveis. Para isso, foram utilizadas uma pesquisa de campo em cinco usinas sucroenergéticas da região de Ribeirão Preto (SP) e também pesquisa bibliografia. A escolha das usinas foi realizada por conveniência e em cada uma foram entrevistados os responsáveis pelas áreas de produção e gestão ambiental;

3. ponderação quantitativa do impacto ambiental relativo de cada resíduo/subproduto identificado na etapa anterior - nesta etapa utilizouse o método Analytic Hierarchy Process (AHP), uma ferramenta de apoio a decisões sobre problemas complexos (SAATY, 1991). A metodologia consiste em montarse uma estrutura hierárquica mostrando os relacionamentos existentes, partindose de um objetivo geral até chegarse às diversas alternativas (CASTRO et al., 2005). O método é baseado em três princípios do pensamento analítico (COSTA; CORREIRA; SOUZA, 2011):

1. construção de hierarquias - o problema deve ser estruturado em níveis hierárquicos, como forma de buscar uma melhor compreensão e avaliação, sendo parte fundamental do processo de raciocínio humano. Identificamse os elementoschave 
para a tomada de decisão, agrupandoos em conjuntos afins, os quais são alocados em camadas específicas;

2. definição de prioridades - o ajuste das prioridades no AHP fundamentase na habilidade do ser humano de perceber o relacionamento entre objetos e situações observadas, comparando pares à luz de um determinado critério (julgamentos paritários);

3. consistência lógica - no AHP é possível avaliar o modelo de priorização construído quanto à sua consistência.

A estruturação de um problema AHP começa com a definição do objetivo global desejado. A partir desse objetivo definemse os critérios em uma estrutura em árvore, sendo o objetivo principal a raiz dessa árvore. À medida que se afasta da raiz, temse os fatores mais específicos e os extremos (as "folhas") representam os critérios de avaliação. Para cada grupo de critérios semelhantes que possuem um mesmo "pai", uma matriz de comparações paritárias (MCP), contendo os níveis de preferência obtidos por comparação de um fator com outro, deve ser preenchida. O princípio do AHP é a geração de um vetor de prioridades pelo cálculo do maior autovetor de cada MCP do problema inteiro (SHIMIZU, 2010). As comparações paritárias são obtidas por questionamento direto às pessoas, que podem ou não ser especialistas, mas que estejam familiarizadas com o problema (SAATY, 1991). Elas não são feitas em escala absoluta devido à natureza dos componentes de uma decisão multicritérios. Dado que muitas vezes o problema é abstrato, isso dificulta que isoladamente os componentes sejam mensurados, principalmente usando a mesma escala. Na comparação dois a dois, quando o tomador de decisão exprimir sua preferência por um atributo " $\mathrm{X}$ ", como sendo muito mais importante do que o atributo "Y”, por exemplo, estará atribuindo para o atributo "X" peso " 5 ". Caso o tomador de decisão considere que os dois critérios possuem a mesma importância, estará atribuindo o peso "1". A Tabela 1 define e explica o conceito dos pesos utilizados no método AHP (OLIVEIRA; COSTA; NETO, 2011).

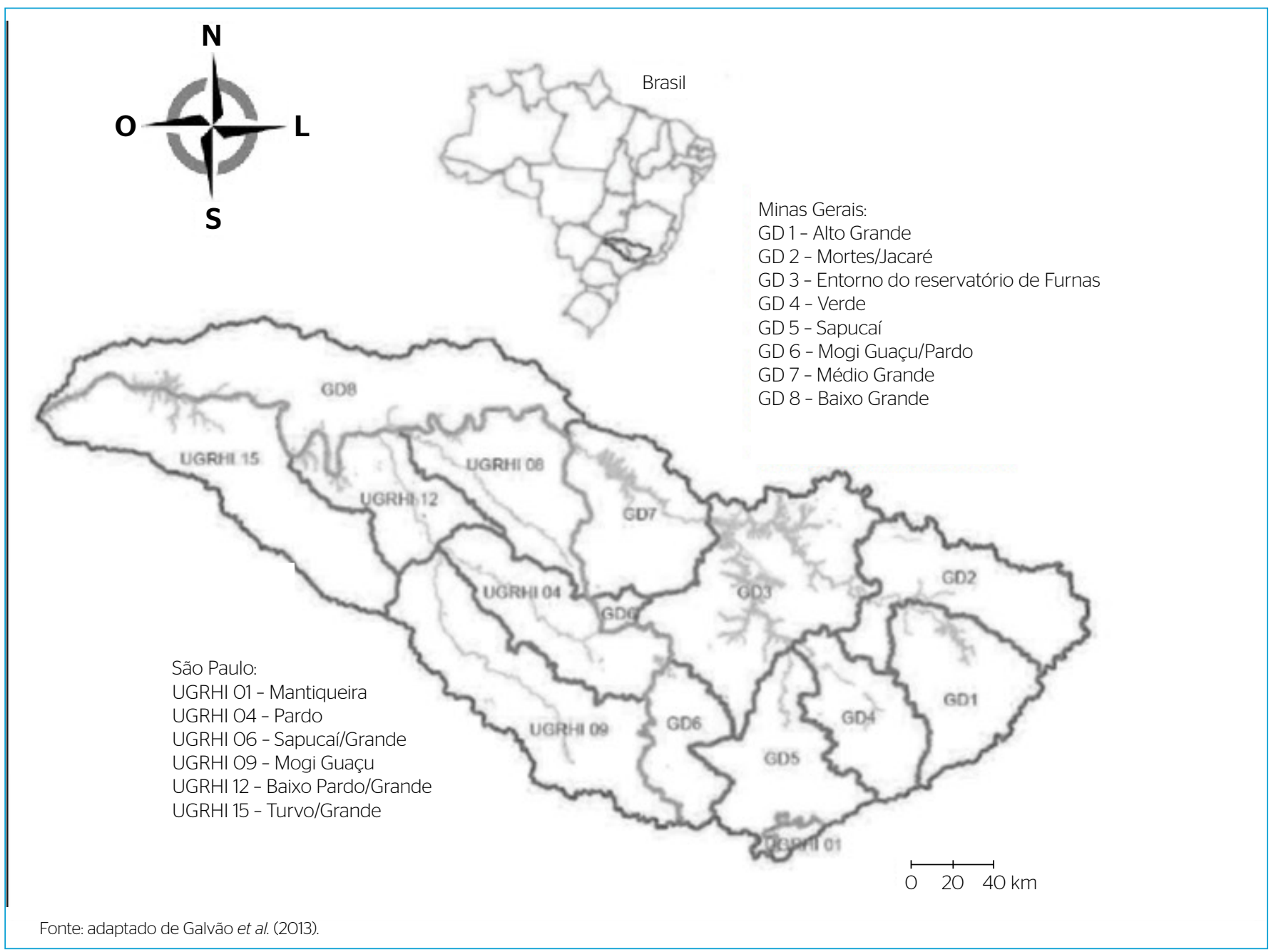

Figura 1 - Localização da Bacia do Rio Mogi Guaçu. 
Para a realização prática dos julgamentos paritários pelo método AHP escolheuse o software Make It Rational (http://makeitrational. $\mathrm{com} /$ features). Esse software foi selecionado por conter uma interface gráfica bastante amigável, por organizar o processo de avaliação multicritérios de maneira bastante lógica e de fácil compreensão, e por calcular automaticamente a razão de consistência (CR) da hierarquia. Para as comparações paritárias contouse com uma equipe de quatro especialistas em gestão ambiental e conhecedores da produção sucroenergética, todos já tendo trabalhado no setor por um período de, pelo menos, quatro anos (Tabela 2). O processo de entrada dos dados no software Make It Rational foi realizado por meio do consenso entre os especialistas, tanto para os critérios de decisão quanto para as alternativas de decisão.

1. avaliação da destinação dos resíduos/subprodutos - as destinações de cada resíduo/subproduto de cada usina foram avaliadas categoricamente. Quando a destinação foi considerada correta, sob o ponto de vista ambiental, a nota atribuída foi 1 (um). Quando a destinação foi considerada incorreta ou indesejável, a nota atribuída foi 0 (zero);

2. elaboração do questionário e coleta de dados - o questionário elaborado teve como objetivo identificar a destinação dada pelas usinas a cada resíduo/subproduto gerado pelos setores de fabricação. Os dados foram coletados nas usinas com os gerentes da área de gestão ambiental e de gestão da produção. Das 25 usinas existentes na BHMG, 14 participaram da pesquisa, o que corresponde a uma amostra de 56\% do universo;

Tabela 1 - Fatores para as comparações paritárias.

\begin{tabular}{|c|c|c|}
\hline $\begin{array}{l}\text { Intensidade de } \\
\text { importância } \\
\text { (peso) }\end{array}$ & Peso & Explicação \\
\hline 1 & Mesma importância & $\begin{array}{l}\text { Os dois atributos contribuem } \\
\text { igualmente para o objetivo }\end{array}$ \\
\hline 3 & $\begin{array}{l}\text { Importância } \\
\text { pequena de um } \\
\text { sobre o outro }\end{array}$ & $\begin{array}{l}\text { A experiência e o julgamento } \\
\text { favorecem levemente um } \\
\text { atributo em relação ao outro }\end{array}$ \\
\hline 5 & $\begin{array}{l}\text { Importância grande } \\
\text { ou essencial }\end{array}$ & $\begin{array}{l}\text { A experiência e o julgamento } \\
\text { favorecem fortemente um } \\
\text { atributo em relação ao outro }\end{array}$ \\
\hline 7 & $\begin{array}{l}\text { Importância muito } \\
\text { grande }\end{array}$ & $\begin{array}{c}\text { Um atributo é fortemente } \\
\text { favorecido em relação ao outro; } \\
\text { sua dominação de importância } \\
\text { é demonstrada na prática }\end{array}$ \\
\hline 9 & $\begin{array}{l}\text { Importância } \\
\text { absoluta }\end{array}$ & $\begin{array}{c}\text { A evidência favorece um } \\
\text { atributo em relação ao outro } \\
\text { com o mais alto grau de certeza }\end{array}$ \\
\hline $2,4,6,8$ & $\begin{array}{l}\text { Valores } \\
\text { intermediários } \\
\text { entre os valores } \\
\text { adjacentes }\end{array}$ & $\begin{array}{c}\text { Quando se procura uma } \\
\text { condição de compromisso } \\
\text { entre duas definições }\end{array}$ \\
\hline
\end{tabular}

Fonte: Oliveira, Costa e Neto (2011, p. 6).
3. quantificação dos resultados finais - a avaliação absoluta consolidada na tabela final reflete o desempenho ambiental de cada usina em termos da correta destinação ambiental de seus resíduos/subprodutos. Essa avaliação foi calculada por meio da multiplicação da ponderação relativa para cada resíduo/subproduto (realizada na etapa três) pela avaliação individual de cada usina relativamente à destinação dada a cada resíduo/subproduto gerado (nota zero ou nota um).

\section{A PRODUÇÃO SUCROENERGÉTICA E SEUS RESÍDUOS E SUBPRODUTOS}

A Figura 2 apresenta simplificadamente as etapas do processo sucroenergético. Os retângulos grafados com linha contínua representam os processos produtivos. Os retângulos com linha tracejada são os resíduos gerados e os que aparecem com linha pontilhada são os subprodutos. Resíduo é tudo o que é produzido e que não pode ser aproveitado economicamente. Já para ser considerado como subproduto a substância ou material deve atender aos seguintes requisitos (FIPA, 2007):

1. existir uma utilização futura;

2. poder ser utilizado diretamente, ou seja, sem sofrer alterações;

3. fazer parte integrante de um processo de produção contínuo.

Tanto os resíduos como os subprodutos podem ser poluentes, pois poluente é o material ou substância introduzida em um sistema natural não adaptada a ele, ou que não suporta as quantidades que nele são despejadas.

Observa-se, pela Figura 2, que a industrialização da canadeaçúcar começa com a recepção da cana. Depois de descarregada a cana é limpa por meio de processo de lavagem com água ou por meio de limpeza a seco. O processo de lavagem com água gera como subproduto o efluente da lavagem da cana. O processo de lavagem a seco gera a palha, a qual é conduzida para a caldeira na cogeração de energia.

Em seguida, decorre a etapa de extração do caldo, geralmente realizada por meio de moendas ou difusores. Por meio da extração separase o caldo da cana (produto) do bagaço (subproduto). O bagaço será também utilizado para alimentar as caldeiras onde será queimado para a cogeração de energia. Nesse processo geramse como subprodutos as

Tabela 2 - Características da equipe de especialistas avaliadores

\begin{tabular}{l|c|c|c} 
Avaliador & $\begin{array}{c}\text { Experiência } \\
\text { na produção } \\
\text { sucroalcooleira }\end{array}$ & $\begin{array}{c}\text { Experiência } \\
\text { em gestão } \\
\text { ambiental }\end{array}$ & Formação \\
\hline A & 5 anos & 7 anos & Engenheiro Agrônomo \\
\hline B & 6 anos & 10 anos & Físico \\
\hline C & 4 anos & 6 anos & Engenheiro Ambiental \\
\hline D & 4 anos & 4 anos & $\begin{array}{c}\text { Engenheiro de } \\
\text { Produção }\end{array}$ \\
\hline
\end{tabular}




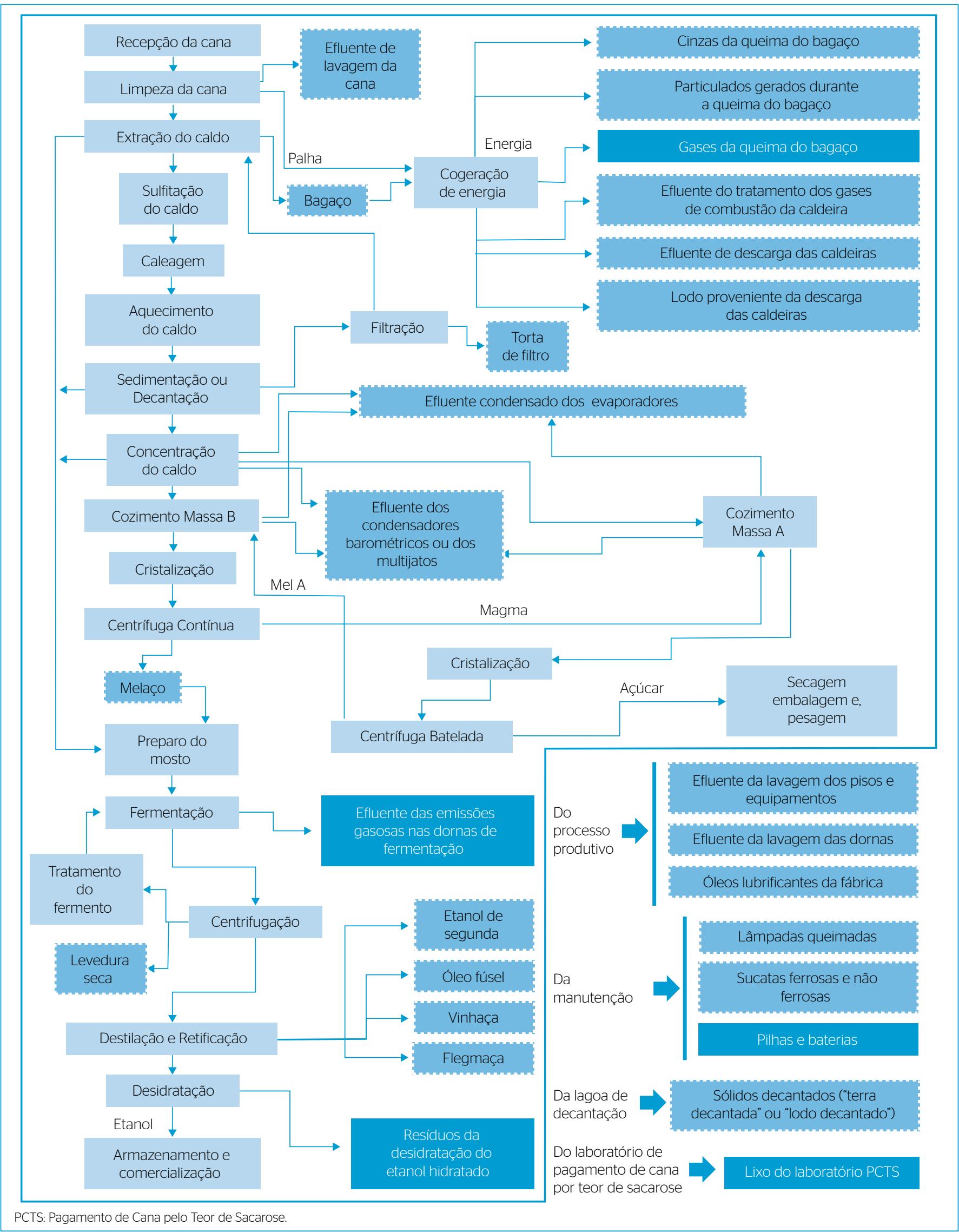

Figura 2 - Fluxograma simplificado da produção industrial sucroenegética com destaque para os resíduos/subprodutos gerados. 
cinzas da queima do bagaço, os materiais particulados que saem pela chaminé, o efluente do tratamento dos gases de combustão, o efluente e o lodo proveniente da descarga das caldeiras. Os resíduos gerados são os gases da queima do bagaço.

O caldo extraído segue ao processo de sulfitação, o qual promove a redução do seu $\mathrm{pH}$ de valores entre 5 e 5,5 para 3,8 e 4,3. Em seguida, o caldo segue ao processo de calagem para elevação do pH e então é aquecido. O aquecimento tem a finalidade de acelerar a coagulação e floculação de coloides e não açúcares proteicos, emulsificar graxas e ceras e possibilitar a degasagem do caldo. Depois de aquecido e adicionado polímero, o caldo clarificado é separado do lodo por meio da sedimentação em decantadores. O lodo do fundo do decantador é enviado para filtração visando a recuperação do açúcar ali contido. Após sair do decantador, o lodo recebe pequena quantidade de polímero, o qual auxilia na separação das impurezas, e recebe também adição de bagacilho com o objetivo de aumentar o rendimento dessa extração. O caldo filtrado retorna para o processo de clarificação e o material retido nos filtros recebe o nome de torta de filtro. Esse subproduto pode ser enviado à compostagem e, a seguir, à lavoura para ser utilizado como adubo (REBELATO; MADALENO; RODRIGUES, 2011).

Depois da decantação seguese a etapa de concentração do caldo (realizada em evaporadores de múltiplo efeito), que consiste na retirada de água do caldo para o aumento da concentração de sólidos solúveis ( ${ }^{\circ} \mathrm{Brix}$ ) para uma faixa entre $60^{\circ}$ e $65^{\circ} \mathrm{Brix}$, quando passa a receber o nome de xarope. O processo de concentração do caldo gera como subprodutos o efluente dos condensadores barométricos ou dos multijatos e o efluente condensado nos evaporadores. O xarope segue para o processo de cozimento, cujo objetivo é cristalizar o máximo da sacarose presente no xarope. Esse esgotamento não pode ser feito somente em um cozimento e, geralmente, as usinas possuem conjuntos de cozedores, normalmente A e B. Cada conjunto de cozedores possui um sistema de cristalização separado e seguido de centrífugas. Para o eixo dos cozedores A observamse as centrífugas "de batelada" e no eixo dos cozedores da massa B temse a centrífuga contínua (REBELATO; MADALENO; RODRIGUES, 2013).

Os aparelhos cristalizadores localizados abaixo dos cozedores têm a função de armazenar a massa cozida (cristais de açúcar mais mel) produzida nos cozedores até a centrifugação. As centrífugas, por sua vez, são responsáveis por separar os cristais do mel. Por meio da centrifugação gerase o mel A e o mel B (ou melaço, que é um subproduto) nas massas A e B, respectivamente. Observase que há adição de mel A no cozedor B e este é concentrado até atingir a supersaturação. Em seguida, adicionase a "semente" (cristais de açúcar quebrados misturados com etanol), que é o método que proporciona maior padronização do tamanho de açúcar final desejado. Para a semente de açúcar "crescer” é necessário que seja adicionada uma maior quantidade de mel A (para aumentar a quantidade de sacarose no meio). Essa alimentação com mel A é realizada até que o tamanho dos cristais seja adequado e tem a função de fornecer água (para não sair da zona metaestável de saturação) e sacarose (para o crescimento do cristal de açúcar). Em seguida, o processo é interrompido e a massa cozida B produzida é enviada aos cristalizadores. Do aparelho de cristalização a massa cozida B é encaminhada para a centrífuga contínua que fará a separação dos cristais do mel. Os cristais são quebrados pela força da ação centrífuga e são encaminhados para a formação do magma, enquanto o melaço é direcionado para a produção de etanol (preparo do mosto) (REBELATO; MADALENO; RODRIGUES, 2011).

O magma vai para o cozedor A e se encontra em supersaturação. Não é necessária a adição de sementes, pois o magma contém os pequenos cristais que crescerão com a alimentação realizada com xarope que vem do processo de concentração do caldo. Após atingir o tamanho desejado dos cristais no cozedor A, a massa cozida é encaminhada para o cristalizador e, em seguida, para a centrifugação na centrífuga "de batelada”. O açúcar comercial é separado e enviado para as etapas finais de produção (secagem, embalagem e pesagem). O mel A, por sua vez, é encaminhado para o armazenamento e será usado no cozedor $\mathrm{B}$ para continuar o processo de esgotamento. Observase que os processos de cozimento (A e B) também são geradores de efluentes dos condensadores barométricos ou dos multijatos e de efluente condensado nos evaporadores (REBELATO; MADALENO; RODRIGUES, 2011).

Na produção do etanol podese utilizar como matériaprima o caldo extraído da cana, o caldo clarificado, o xarope ou o melaço. A produção do etanol se inicia com o preparo do mosto. Esse preparo começa com a correção da concentração da matériaprima utilizada com a redução do $\mathrm{pH}$ para 4,5, com o acerto da temperatura para em torno de $32^{\circ} \mathrm{C}$, e com o suprimento de deficiências nutricionais. Após a etapa de preparo do mosto realizase a mistura deste com fermento da espécie Saccharomyces cerevisiae e iniciase a etapa de fermentação. Por meio desse processo obtémse o vinho levedurado. Em seguida, esse vinho passará pela centrifugação com o objetivo de separar o vinho da levedura. Uma parte do fermento é encaminhada para o setor de tratamento para diminuir a contaminação com bactérias e utilizar novamente o levedo em um novo ciclo de fermentação. Outra parte do fermento, resultante da multiplicação das leveduras durante o processo fermentativo, é direcionada para o processo de secagem para produção de levedura seca (subproduto) (REBELATO; MADALENO; RODRIGUES, 2012).

Durante o processo de fermentação também há produção do gás $\mathrm{CO}_{2}$, que pode ser considerado um efluente das emissões gasosas nas dornas de fermentação. O gás arrasta etanol e deve passar pela torre de $\mathrm{CO}_{2}$ para recuperar o álcool arrastado. O vinho delevurado (sem levedura) é então encaminhado para o processo de destilação. 
A destilação consiste na separação das substâncias que compõem o vinho, basicamente água, etanol, álcoois superiores, ácidos orgânicos, aldeídos, ésteres e outros por meio de seus diferentes pontos de ebulição. Em primeiro lugar, o vinho é levado para a destilação na coluna "A/A1/D", na qual se injeta vapor e vinho quente e são obtidas três saídas:

1. a vinhaça;

2. o etanol "de segunda", uma mistura hidro alcoólica com teor de $92^{\circ}$ a $94^{\circ} \mathrm{GL}$, que sai no topo da coluna (D);

3. a flegma, uma mistura de vapores hidro alcoólicos de $45^{\circ}$ a $50^{\circ} \mathrm{GL}$, que sai da lateral (entre as colunas A1 e A) e é submetido a um segundo processo de destilação, o de retificação (MARAFANTE, 1993).

Na segunda destilação, realizada na coluna "B/B1", elevase o grau alcoólico e eliminase parte das impurezas. Nessa etapa temse a produção de etanol hidratado (92,6 INPM), de flegmaça (subproduto da retificação da flegma), de óleo fúsel (subproduto) e de etanol "de segunda". O processo prossegue rumo à produção do etanol anidro (99,3 INPM ou 99,6\% v/v) por meio de sua desidratação na coluna "C" (MARAFANTE, 1993).

Existem três métodos para desidratar o etanol hidratado: o extrativo, o azeotrópico e a peneira molecular. No primeiro caso são adicionadas substâncias que aprisionam a água e assim possibilitam separar a água do etanol na destilação. A substância mais utilizada nesse método é o monoetilenoglicol (MEG). No método azeotrópico utilizase o ciclohexano, o qual gera uma substância ternária de menor ponto de ebulição, retendo então a molécula de água. Esses dois métodos de desidratação são utilizados na coluna $\mathrm{C}$ e os produtos utilizados são recuperados na coluna P. Quando se utiliza o MEG, o etanol anidro é retirado no topo da coluna $\mathrm{C}$, enquanto quando se utiliza o ciclohexano, o etanol de graduação 99,6\% v/v sai na base da coluna C. Nos dois métodos as substâncias adicionadas são recuperadas e reutilizadas. A peneira molecular, terceiro método, possui elevada capacidade de adsorção seletiva porque é constituída de um mineral especial, denominado zeólita, para esse fim. Esse equipamento é construído de forma a reter a água na medida em que o etanol passa. Retirase, por meio desse método, etanol anidro de alta qualidade, sem resíduos químicos. Por isso, é o método preferido para o etanol que é exportado (REBELATO; MADALENO; RODRIGUES, 2012).

Após o processo de destilação o etanol é enviado para tanques especiais de armazenamento. Depois de comercializado, o etanol hidratado ou anidro é transportado até as empresas distribuidoras e, por fim, chega ao consumidor final.

A partir dos processos produtivos identificouse também a geração de três subprodutos:

1. o efluente da lavagem dos pisos e equipamentos, gerados na limpeza de equipamentos e pisos;

2. o efluente da lavagem das dornas, produzido na assepsia das dornas (processo descontínuo de fermentação);
3. os óleos lubrificantes da fábrica, que são os óleos trocados periodicamente de máquinas como turbinas, sistemas hidráulicos, engrenagens, etc. Finalmente, das lagoas de decantação há a geração de sólidos decantados ("terra decantada" ou "lodo decantado").

Esses sólidos decantados são geralmente coletados e enviados à lavoura como adubo. Das operações de manutenção são coletadas lâmpadas queimadas, sucatas ferrosas e não ferrosas e pilhas e baterias, todos subprodutos recicláveis. Do laboratório de pagamento de cana por teor de sacarose gerase um resíduo (lixo) que normalmente é destinado a aterros sanitários.

\section{RESULTADOS E DISCUSSÃO}

Com vistas à ponderação quantitativa do impacto ambiental relativo de cada resíduo/subproduto foi criada uma estrutura hierárquica direcionada pelas três entidades ambientais básicas: solo, água e atmosfera. Estas figuraram como os critérios de avaliação, os quais foram utilizados como balizadores na avaliação paritária das alternativas. Essas alternativas são os 27 resíduos/subprodutos identificados anteriormente (Figura 2). A estrutura hierárquica pode ser vista na Figura 3. Na ponderação quantitativa do impacto ambiental relativo de cada resíduo/ subproduto por meio do método AHP considerouse o impacto potencial dos resíduos/subprodutos tomando como hipótese cada despejo sendo lançado diretamente no meio ambiente. Por exemplo, na comparação paritária entre a vinhaça e a flegmaça, sob o ponto de vista do critério do "impacto na água", tomaramse como hipótese ambos os efluentes sendo despejados diretamente em cursos de água. Neste caso, os avaliadores ponderaram uma relação de 7:1, ou seja, a alternativa "vinhaça" foi considerada (Tabela 1) fortemente dominante com relação à alternativa "flegmaça". Isso porque a vinhaça é um resíduo altamente poluidor, o qual apresenta altíssimos níveis de demanda bioquímica de oxigênio (DBO), enquanto a flegmaça é constituída basicamente por água com traços de óleo fúsel e baixos níveis de DBO.

A Figura 4 apresenta os resultados das comparações paritárias feitas por meio do software Make it Rational considerandose os critérios já citados: impacto na atmosfera, impacto na água e impacto no solo. A partir das ponderações feitas pela equipe de especialistas, a produção industrial sucroenergética apresentou maior impacto ambiental relativo nas águas $(67,4 \%)$, seguido por solo $(22,6 \%)$ e atmosfera $(10,07 \%)$. A Figura 5 mostra uma visualização gráfica da ponderação do impacto ambiental relativo entre todos os resíduos/subprodutos. O teste de consistência calculado pelo software para os pesos relativos de cada resíduo/ subproduto revelou uma taxa de consistência (CR) de 0,082. Uma taxa de consistência de 0,10 ou menos é considerada aceitável (SAATY, 1991).

A seguir, apresentamse os resíduos/subprodutos com seus pesos individuais relativos referentes à Figura 5 (pesos entre parênteses), uma 
descrição dos impactos potenciais e também a avaliação realizada para a destinação de cada resíduo/subproduto praticada pelas usinas com a respectiva nota:

- Vinhaça $(8,90 \%)$ - efluente de elevado potencial de contaminação, tanto do solo como de qualquer tipo de manancial, seja superficial ou subterrâneo, pois é riquíssimo em matéria orgânica (variando de 20.000 a $35.000 \mathrm{mg} / \mathrm{L}$ ) e tem $\mathrm{pH}$ ácido, na faixa de 5 a 5,5. Todas as usinas alegam cumprir a norma CETESB P4.231 no gerenciamento da vinhaça. Destinos considerados ambientalmente corretos (nota 1).

- Pilhas e baterias (6,70\%) - resíduo que contém metais pesados como o chumbo, mercúrio, níquel e cádmio, com alto potencial para contaminar solo e águas. Todas as usinas alegam encaminhar este resíduo a empresas credenciadas. Destinos considerados ambientalmente corretos (nota 1 ).

- Etanol de segunda (6,62\%) - subproduto altamente contaminante de solo e águas por conter ácidos, aldeídos, furfural, ésteres, álcoois superiores e substâncias constituídas de amoníaco e aminas. Os destinos verificados foram: reprocesso do etanol bruto ou venda. Destinos considerados ambientalmente corretos (nota 1 ).

- Óleos lubrificantes da fábrica (6,23\%) - apresentam hidrocarbonetos e metais, tais como o ferro, chumbo, zinco, cobre, cromo, níquel e cádmio. Se lançado no solo, o óleo se infiltra levado pela água da chuva. Além de contaminar o solo, vai contaminar os lençóis freáticos subterrâneos. Se lançado nas águas superficiais, dá origem a uma camada que impede a oxigenação da água e a fotossíntese das plantas aquáticas, que por sua vez nutrem os peixes. Todas as usinas alegam encaminhar este resíduo a empresas especializadas em rerrefino do óleo. Destinos considerados ambientalmente corretos (nota 1$)$.
- Lâmpadas queimadas (5,98\%) - resíduo geralmente rico em mercúrio (metal pesado) com alto potencial de contaminação de solo, águas, plantas e animais. Os destinos verificados foram: aterro industrial ou encaminhamento a empresas especializadas em reciclagem. Destinos considerados ambientalmente corretos (nota 1 );

- Melaço (5,90\%) - é constituído principalmente de açúcares como frutose, glicose e sacarose que não foi cristalizada na produção de açúcar. Apesar de poder ser utilizado como fertilizante (em sua composição estão presentes nitrogênio, fosfatos, cálcio e magnésio bem como zinco, manganês, cobre, ferro e micronutrientes) e como alimento para animais, é muito poluente por ser muito concentrado, com até $85^{\circ} \mathrm{Brix}$, portanto com $\mathrm{DBO}$ elevada. Os destinos verificados foram: venda ou encaminhamento para fabricação do etanol. Destinos considerados ambientalmente corretos (nota 1).

- Óleo fúsel (5,36\%) - efluente potencialmente poluidor de águas e solo composto basicamente por álcool isoamílico, álcool isobutílico, álcool namílico, álcool nbutílico, isopropanol, furfural aldeídos e ácidos graxos. Doze usinas declaram vender o óleo fúsel e,

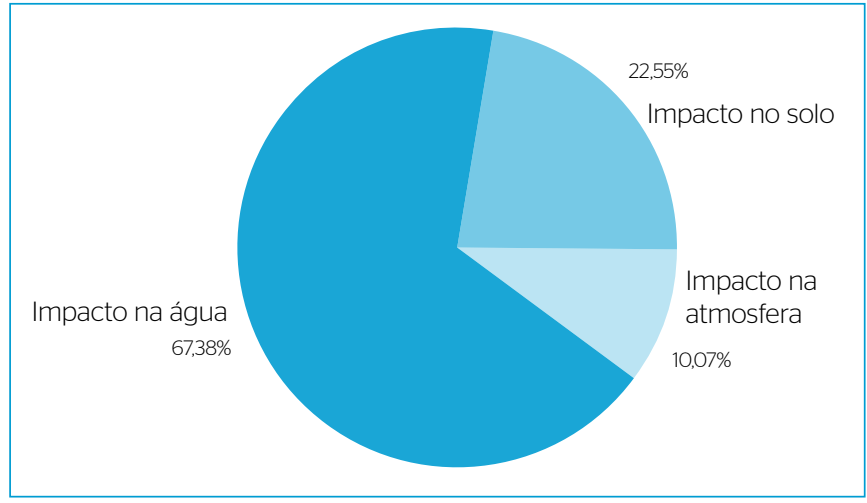

Figura 4 - Resultados das comparações paritárias entre os critérios da hierarquia criada.

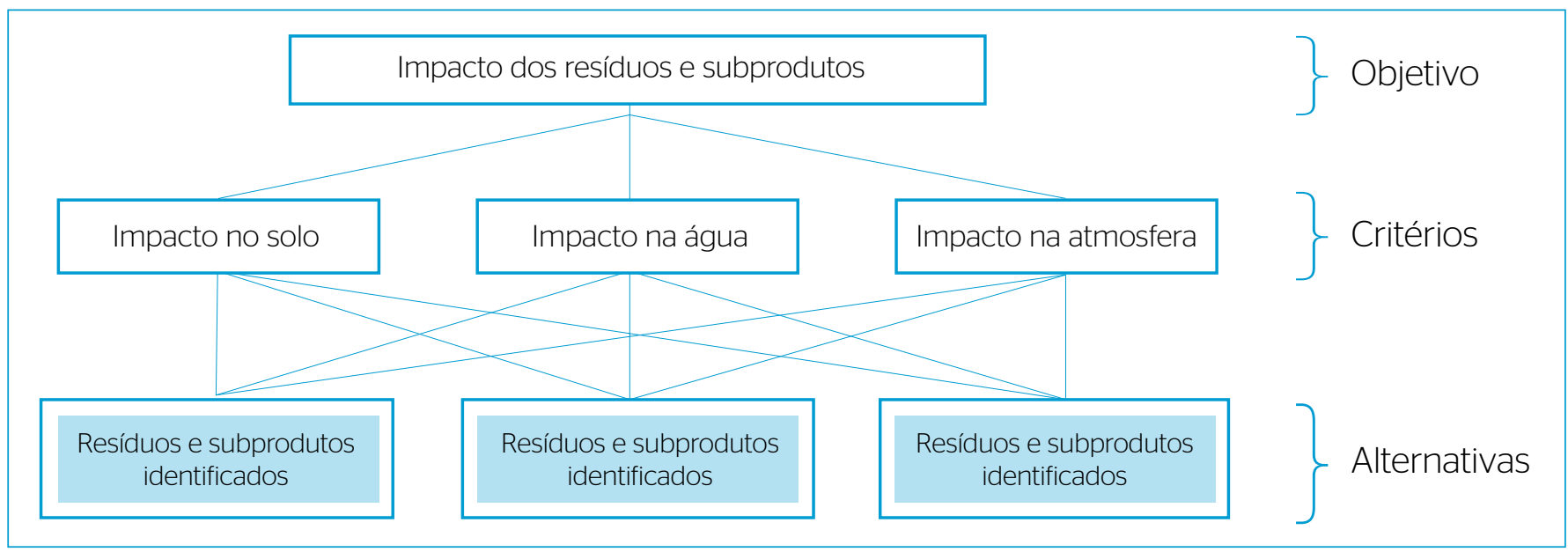

Figura 3 - Estrutura hierárquica para a ponderação dos resíduos e subprodutos. 
portanto, receberam nota 1. Duas delas descartam nas águas residuárias e, portanto, receberam nota zero.

- Lixo de laboratório Pagamento de Cana pelo Teor de Sacarose (PCTS) (5,09\%) - são soluções clarificantes à base de alumínio, resíduos de papel de filtro, bolo úmido (análise de fibra), cinzas das análises de impureza mineral e reagentes da análise de quantidade de açúcares redutores. São potencialmente poluidores de águas e solo. Os destinos verificados foram: descarte em aterro industrial (sete usinas) ou recolhimento por empresa especializada (sete usinas). Destinos considerados ambientalmente corretos (nota 1).

- Bagaço (4,45\%) - pela degradação da celulose, da hemicelulose e da lignina pode ter efeito enormemente poluidor nas águas se for descartado nesse meio, podendo aumentar significativamente os níveis de DBO. É um subproduto composto basicamente por fibra (celulose) e água, contendo também certa quantidade de açúcar (2 a 3\% do peso úmido do bagaço) e pH baixo (ao redor de 5,6). Todas as usinas destinam o bagaço às caldeiras para produção de energia e, quando há excedente, vendemno. Destinos considerados ambientalmente corretos (nota 1).

- Sucatas ferrosas e não ferrosas $(3,88 \%)$ - metais ferrosos e não ferrosos como alumínio, cobre, bronze, níquel, zinco são potencialmente contaminantes de águas e solo, tanto por meio da absorção por parte das plantas como por adsorção por argilas e matéria orgânica e lixiviação pela água. Todas as usinas (exceto uma) destinam este tipo de material às empresas de reciclagem.

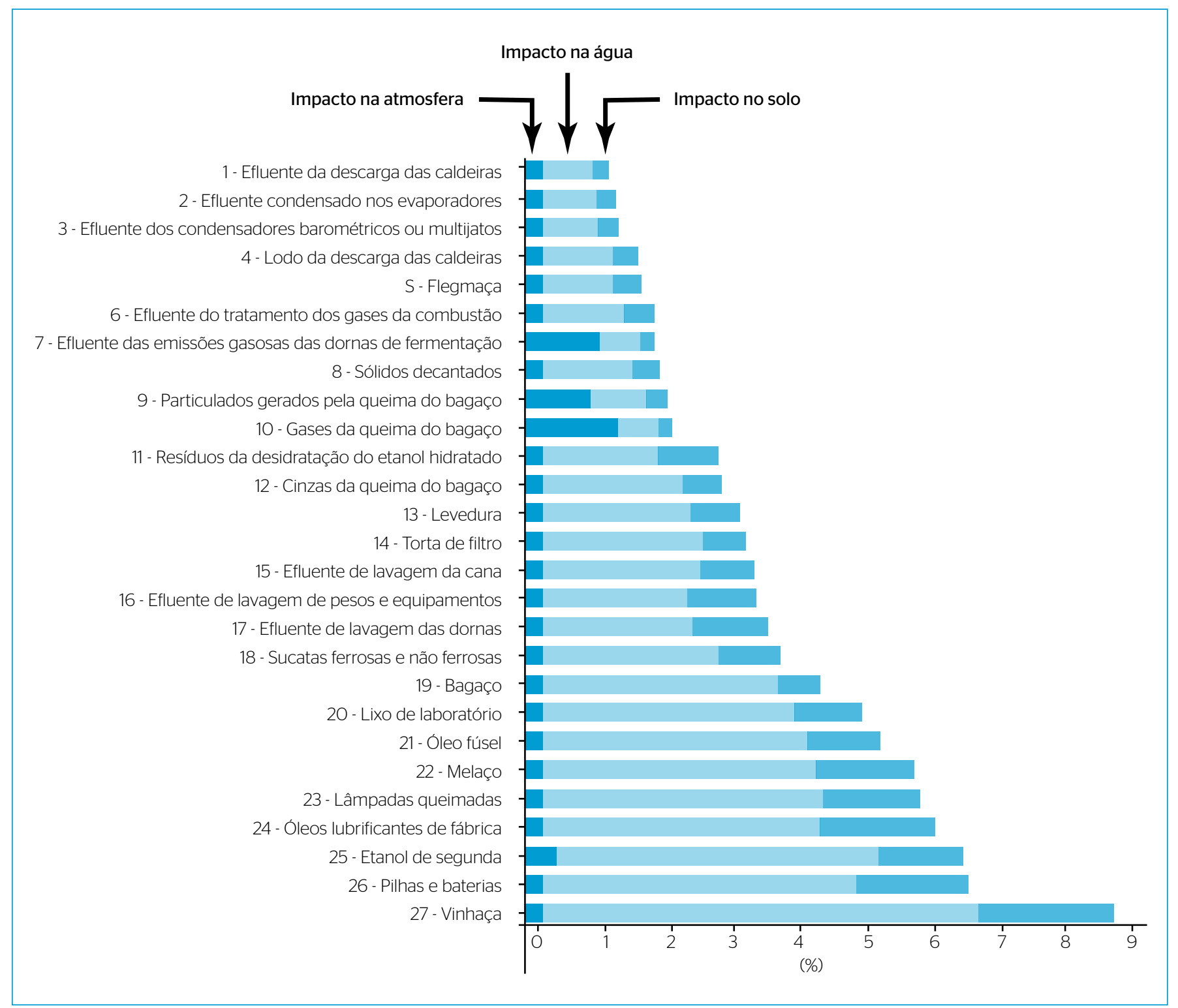

Figura 5 - Resultados gráficos da ponderação do impacto ambiental relativo entre os 27 resíduos e subprodutos. 
Uma delas descarta apenas a sucata não ferrosa em aterro industrial. Destinos considerados ambientalmente corretos (nota 1).

- Efluente de lavagem das dornas (3,66\%) - considerase que a água de lavagem das dornas tem efeito poluidor análogo ao do vinhoto, entretanto bem mais diluído, cerca de $20 \%$ do vinhoto. Uma das usinas retorna este efluente à dona volante. Outra usina não produz este efluente. As 12 restantes encaminham o efluente à lavoura. Destinos considerados ambientalmente corretos (nota 1 ).

- Efluente da lavagem de pisos e equipamentos (3,50\%) - efluente de características não uniformes. A DBO varia na faixa de centenas até milhares de mg. $\mathrm{L}^{1}$, e o pH, desde muito ácido até muito alcalino. Pode também estar contaminado com graxas e óleos. Tratase de um efluente com alto potencial de contaminação das águas e do solo. Uma das usinas agrega o efluente à água de lavagem da cana. Duas delas o encaminham às águas residuárias. Todas as outras destinam o efluente à lavoura. Portanto, receberam nota 1 .

- Efluente da lavagem da cana (3,47\%) - efluente caracterizado por altas taxas de DBO, muita matéria orgânica, alta concentração de sólidos e pH baixo. Quatro usinas não produzem tal efluente. As dez restantes o gerenciam em circuito fechado e fertirrigação. Destinos considerados ambientalmente corretos (nota 1).

- Torta de filtro $(3,35 \%)$ - subproduto cujas características são afetadas por: estágio de maturação e variedade da cana, tipo de solo utilizado, variações no processo de clarificação do caldo, entre outros. O nitrogênio orgânico, cálcio e fósforo estão entre os elementos principais. Constituise por bagaço de cana (11\% de lignina, $34 \%$ de hemicelulose e $38 \%$ de celulose) com pequena fração mineral (principalmente silício). Tem alto potencial poluente principalmente com relação às águas, podendo acarretar significativos danos aos mananciais superficiais ou subterrâneos, se indevidamente disposta no ambiente. Todas as usinas destinam este subproduto à lavoura de cana. Destinos considerados ambientalmente corretos (nota 1 ).

- Levedura (3,26\%) - subproduto rico em proteínas e concentrado em vitaminas do complexo B, largamente utilizado na composição de ração para animais e muito utilizada na indústria alimentícia. Como mais de $87 \%$ do peso sobre a matéria seca é composto de matéria orgânica, tratase de material potencialmente poluidor, principalmente de águas superficiais e subterrâneas. Nove usinas vendem este subproduto. Quatro delas o incorporam à vinhaça para fertirrigação. Uma delas ou vende ou o incorpora à vinhaça. Destinos considerados ambientalmente corretos (nota 1 ).

- Cinzas da queima do bagaço (2,98\%) - apesar de quimicamente estável, não tóxica, e não conter material orgânico dissolvido, as cinzas são potencialmente poluidoras de águas superficiais. O dióxido de silício $\left(\mathrm{SiO}_{2}\right)$ é o composto predominante (60\% da massa), representando os óxidos de potássio $\left(\mathrm{K}_{2} \mathrm{O}\right)$, óxidos de magnésio $(\mathrm{MgO})$, óxidos de fósforo $\left(\mathrm{P}_{2} \mathrm{O}_{5}\right)$ e óxidos de cálcio $(\mathrm{CaO})$ conjuntamente, cerca de $32 \%$ da massa da cinza. Todas as usinas destinam as cinzas das caldeiras à lavoura. Destinos considerados ambientalmente corretos (nota 1).

- Resíduos da desidratação do etanol hidratado (2,91\%) - a resina zeolítica fica inerte depois de acabar o poder de adsorção e transformase em uma rocha com alumínio e sílica. Não tem efeito poluidor na atmosfera, e tem baixo potencial poluidor nas águas e solo, porém nas águas pode causar assoreamento. Apenas duas usinas declaram possuir este resíduo. Eles são encaminhas a aterro industrial. Destinos considerados ambientalmente corretos (nota 1 ).

- Gases da queima do bagaço (2,23\%) - resíduo gasoso composto por monóxido de carbono $(\mathrm{CO})$, óxidos de nitrogênio $\left(\mathrm{NO}_{\mathrm{x}}\right)$, dióxido de carbono $\left(\mathrm{CO}_{2}\right)$ e uma pequena parcela de dióxido de enxofre $\left(\mathrm{SO}_{2}\right)$. Os gases provenientes da queima do bagaço de todas as usinas são expelidos pelas chaminés. Apesar de atualmente existir tecnologia disponível para a contenção total desses gases, os custos de implantação são altíssimos e poderiam inviabilizar financeiramente o negócio. A liberação dos gases na atmosfera, respeitados os limites de algumas emissões, é uma prática considerada legal pelos órgãos reguladores ambientais. Entretanto, os gases emitidos pela queima do bagaço têm efeito poluidor na atmosfera. Destinos considerados ambientalmente inadequados (nota 0 ).

- Particulados gerados pela queima do bagaço (2,13\%) - tratase de material constituído por partículas de fuligem, pequenos fragmentos de bagacilho não totalmente queimado e sílica. Esses fragmentos particulados possuem relativo grau poluente na atmosfera. Enquanto os materiais mais pesados e grosseiros podem depositarse em áreas mais próximas à usina, os materiais particulados menores e mais leves podem dispersarse remotamente. Todas as usinas declaram cumprir as resoluções do Conselho Nacional do Meio Ambiente (CONAMA) relativas à lavagem dos gases provenientes da combustão do bagaço. Destinos considerados ambientalmente corretos (nota 1 ).

- Sólidos decantados (2,04\%) - nas lagoas de decantação, as águas residuárias da fabricação sucroalcooleira são depositadas de forma que os sólidos em suspensão, com maior massa específica que o líquido em tratamento, possam decantar gradualmente. Os materiais flutuantes, como graxas e óleos, com menor massa específica que o líquido em tratamento sobem para a superfície e dessa forma podem ser separados e conduzidos à armazenagem específica. O principal risco contaminante 
reside nas águas superficiais, pois se trata de lama misturada a sólidos, porém com taxa de DBO muito variada. Todas as usinas declaram enviar os sólidos decantados das lagoas à lavoura de cana. Destinos considerados ambientalmente corretos (nota 1$)$.

- Efluente das emissões gasosas das dornas de fermentação (1,94\%) - constituído basicamente pelo gás $\mathrm{CO}_{2}$ produzido pela fermentação do mosto. Os reatores de fermentação com milhares de litros liberam quantidades expressivas de $\mathrm{CO}_{2}$ no ambiente. Há a estimativa de que para cada $92 \mathrm{~g}$ de etanol fabricado, são lançados $88 \mathrm{~g}$ de gás carbônico na atmosfera. Apesar de existir atualmente tecnologia para captura e armazenamento desse $\mathrm{CO}_{2}$, são raras as usinas que o fazem. Todas as usinas liberam este efluente gasoso na atmosfera. Destinos considerados ambientalmente incorretos (nota 0 ).

- Efluente do tratamento dos gases da combustão (1,94\%) - tratase de efluente que, apesar de conter certo teor de matéria orgânica, apresenta baixa taxa de DBO (de 100 a 300 mg.L ${ }^{1}$ DBO). É um efluente muito quente (temperatura até $80^{\circ} \mathrm{C}$ ) e com alta carga de fuligem, o que não permite seu despejo diretamente em corpos d'água nem na lavoura. Dez usinas declaram utilizar este efluente em circuito fechado e fertirrigação da lavoura. Quatro delas o enviam à lavoura junto com a vinhaça. Destinos considerados ambientalmente corretos (nota 1 ).

- Flegmaça (1,75\%) - a flegmaça é composta por água com traços de óleo de fúsel com baixo potencial poluente. Apontase uma produção média 2,8 L de flegmaça para cada litro de etanol produzido. Seis usinas retornam este efluente à cabeça da coluna A. Oito usinas encaminham o efluente à lavoura. Destinos considerados ambientalmente corretos (nota 1 ).

- Lodo da descarga das caldeiras (1,69\%) - tratase de um resíduo sólido vertido na forma de lodo, composto basicamente por sílica, cálcio e magnésio. É um resíduo potencialmente pouco poluente para o solo ou para os mananciais. Algumas usinas, dada a tecnologia da caldeira em uso, com alto nível de tratamento e controle das características da água de suas caldeiras, não produzem tal resíduo. Três usinas não produzem tal resíduo. Onze usinas o encaminham à lavoura. Destinos considerados ambientalmente corretos (nota 1 ).

- Efluente dos condensadores barométricos ou multijatos (1,42\%) - efluente com baixo potencial poluente, pois há baixa carga orgânica, baixa DBO (até $40 \mathrm{mg} . \mathrm{L}^{1} \mathrm{DBO}$ ), com temperaturas moderadas (em torno de $45^{\circ} \mathrm{C}$ ). Dez usinas reutilizam este efluente em circuito fechado. Quatro usinas o encaminham à lavoura. Destinos considerados ambientalmente corretos (nota 1).

- Efluente condensado nos evaporadores (1,35\%) - Efluente com baixa DBO e baixo risco de contaminação de águas ou solo. Quatro usinas utilizam este efluente nas caleiras. Duas delas encaminham o efluente à lavoura. Nove delas o reutilizam como vapor vegetal ou vapor V3. Destinos considerados ambientalmente corretos (nota 1$)$;

- Efluente da descarga das caldeiras (1,27\%) - tratase de um efluente com DBO muito baixa, porém concentrado em lodo e em sólidos solúveis, não devendo ser despejado em mananciais. Quatro usinas utilizam este efluente em circuito fechado. Duas usinas reutilizam em outras etapas do processo. Oito delas o enviam à lavoura. Destinos considerados ambientalmente corretos (nota 1).

A Tabela 3 apresenta a avaliação categórica de cada usina para cada resíduo/subproduto. A tabela também traz a ponderação relativa de cada resíduo/subproduto e a avaliação absoluta de cada um deles (última linha da tabela). Na última coluna, à direita, é possível ver as avaliações absolutas individuais de cada usina. No extremo direito inferior verificase a avaliação quantitativa final média de todas as usinas, sob o ponto de vista da destinação dos despejos. Avaliouse que as usinas pesquisadas destinam corretamente, em média, 95\% dos resíduos/ subprodutos que geram.

\section{CONSIDERAÇÕES FINAIS}

A indústria sucroenergética, produtora de açúcar, etanol e energia, além de outros subprodutos comercializáveis, emprega métodos e processos produtivos de alto potencial de impacto no meio ambiente. Tratase de um tipo de indústria que tem adotado inovações na gestão de seus resíduos industriais, tanto por conta da imposição de novas leis quanto pela conscientização dos empreendedores do setor relativamente às questões ambientais.

A partir da primeira etapa de produção industrial, a recepção da cana, até a última etapa, o armazenamento do açúcar e do etanol, este trabalho identificou 27 resíduos/subprodutos gerados. Tanto os resíduos como os subprodutos podem ser ou não poluentes. Isso depende da capacidade do sistema natural em suportar as quantidades de material nele introduzido. Esses resíduos/subprodutos foram tomados como as alternativas a serem ponderadas com relação aos critérios: impacto nas águas, impacto no solo e impacto na atmosfera. A ponderação do impacto ambiental relativo de cada um deles é um problema de resolução complexa, pois classificação apreciativa dos poluentes gerados encerra tanto o conhecimento das consequências em termos de impactos no ambiente como também a reflexão comparativa entre essas consequências. Tratase de um problema que envolve: resíduos/subprodutos com grandes diferenças na natureza química e física; diversos efeitos nocivos que estes podem ter se mal destinados em diferentes ambientes naturais (águas, solo e atmosfera); 
Tabela 3 - Avaliação categórica de cada usina para cada resíduo/subproduto.

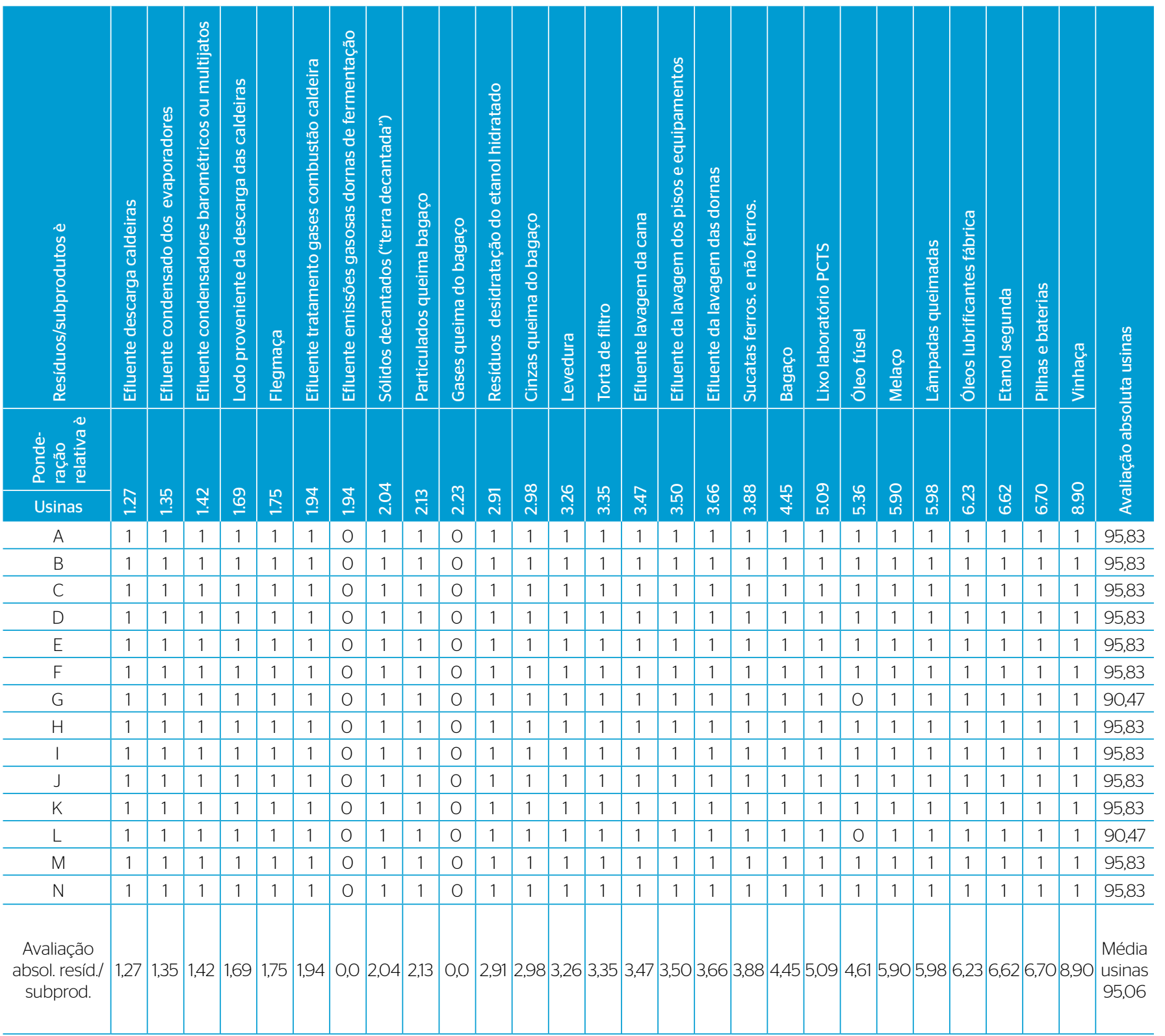

PCTS: Pagamento de Cana pelo Teor de Sacarose.

e alterações que esses efeitos que podem ter com o passar do tempo. A partir da ponderação realizada, concluise que a produção sucroenergética tem alto potencial de contaminação dos mananciais superficiais e subterrâneos, médio potencial de contaminação do solo e pequeno potencial de contaminação da atmosfera.

No trabalho de avaliação final de cada usina a partir da destinação de cada poluente não foram adotados como padrões (de análise) simplesmente as leis e resoluções legais pertinentes. Isso porque elas são insuficientes como base para se julgar a adequabilidade da destinação dos despejos. Por exemplo, duas constatações de inadequações foram com relação aos gases emitidos. Levando em conta que os efluentes das emissões gasosas da fermentação (gás $\mathrm{CO}_{2}$ ) são liberados diretamente no ambiente, não se pode dizer, sob um ponto de vista ortodoxo, que essa emissão seja ambientalmente correta. O mesmo vale para os gases exauridos pelas chaminés das caldeiras de combustão do bagaço. Mesmo que não haja leis ou resoluções que regulamentem a proibição dessas emissões na atmosfera, sabese que os gases expelidos são causadores do efeito estufa e que, portanto, essas emissões não podem ser ambientalmente adequadas. Analogamente, para o caso do 
óleo fúsel, observouse que duas usinas destinam este subproduto à lavoura. Apesar do baixo volume produzido, $250 \mathrm{~mL}$ de óleo fúsel por $100 \mathrm{~L}$ de etanol em média, esta não se constitui em uma destinação adequada.

Levando em conta todas as observações no caso das empresas em estudo, concluise que, com base nos conhecimentos científicos atestados até o presente momento em termos de impactos ambientais de cada poluente, as destinações dos resíduos/subprodutos das usinas são em média 95\% adequadas.

\section{AGRADECIMENTOS}

Os autores agradecem à Fundação de Amparo à Pesquisa do Estado de São Paulo (FAPESP), pelo apoio financeiro à pesquisa.

\section{REFERÊNCIAS}

AGÊNCIA NACIONAL DE AGUAS - ANA. (2012) Manual de conservação e reúso da água na agroindústria sucroenergética. Brasília: Agência Nacional das Águas - FIESPÚNICACTC. Disponível em: <www.iesp.com.br/ambiente/ downloads/publicaguab.pdf>. Acesso em: 13 abr. 2012.

CASTRO, S.O; MOREL, E.P; LEÃO, G.T;:SELLITTO, M.A. (2005) Metodologia para avaliação de desempenho ambiental em fabricação utilizando um método de apoio à decisão multicriterial. Estudos Tecnológicos, v. 1, n. 2, p. 2129.

COSTA, J.F.S; CORREIA, M.G.; SOUZA, L.T.T. (2011) Utilização do método de análise hierárquica na escolha de software estatístico para a demanda de uma universidade pública. Produto \& Produção, v. 12, n. 1, p. 4259.

FEDERAÇÃO DAS INDÚSTRIAS PORTUGUESAS AGROALIMENTARES FIPA. (2007) Boletim informativo da Federação das Indústrias Portuguesas Agroalimentares Disponível em: <http://www.fipa.pt/pdf/fipaflash95.pdfs. Acesso em: 5 jan. 2013.

GALVÃO, A.Q; FREITAS, J.C; VICTORIA, N.G; BUSER, T.B. (2O13) Plano da bacia do Rio Mogi Guaçu. Escola Politécnica da Universidade de São Paulo. Disponivel em: <http://200.144.189.97/phd/LeArq.aspx?id_arq=5059> Acesso em: 13 fev. 2013.

MACHADO, A.G.C. \& SILVA, J.C. (2010) Estratégia empresarial e práticas ambientais: evidências no setor sucroalcooleiro. Revista Brasileira de Gestão de Negócios, v. 12, n. 37, p. 405424.

MARAFANTE, L.J. (1993) Tecnologia da fabricação do açúcar e do álcool. São Paulo: Icone. 327p.

MILARÉ, E. (2000) Direito do Ambiente. São Paulo: Editora dos Tribunais. 322p.

OLIVEIRA, S.M.; HANSEN, A.O; SILVA, T.N.; PEDROZO, E.A:; BOLDIN, V.P. (2009) Responsabilidade socioambiental no setor sucroalcooleiro: um estudo de caso na Pioneiros Bioenergia S/A. Revista Eletrônica de Gestão, v. 2, n. 1, p. 111134.

OLIVEIRA, A.A; COSTA, J.A.F; SOUSA NETO, M.V. (2011) Aplicação do

método de análise hierárquica na tomada de decisão para a adoção de computação em nuvem. In: SIMPOI, 2011. São Paulo: FGVEAESP.

PIACENTE, F.J. (2005) Agroindústria canavieira e o sistema de gestão ambiental: o caso das usinas localizadas nas Bacias Hidrográficas dos rios Piracicaba, Capivari e Jundiaí. Campinas. Dissertação (Mestrado) - Programa de PósGraduação em Desenvolvimento Econômico, Universidade Estadual de Campinas.
REBELATO, M.G; MADALENO, L.L; RODRIGUES, A.M. (2011) Um estudo sobre a aplicabilidade do sistema puxado de produção na fabricação de açúcar. Revista Gestão Industrial, v. 7, n. 1, p. 228246.

REBELATO, M.G; MADALENO, L.L; RODRIGUES, A.M. (2O12) Um estudo sobre a aplicabilidade do JustlnTime na fabricação do etanol. Revista Produção Online, v. 12, n. 3, p. 703728

REBELATO, M.G.; MADALENO, L.L; RODRIGUES, A.M. (2013) Proposta de indicadores para avaliação do desempenho ambiental dos processos produtivos de usinas sucroenergéticas. 4th International Workshop Advances in Cleaner Production, v. 4, p. 110.

RODRIGUES, I.C. (2004) Certificação ambiental e desenvo/vimento sustentável: avaliação para o setor sucroalcooleiro localizado na bacia hidrográfica do rio Mogi Guaçu - SP. São Carlos. Tese (Doutorado) - Programa de PósGraduação em Engenharia de Produção, Universidade Federal de São Carlos.

ROHRICH, S.S. \& CUNHA, J.C. (2004) A Proposição de uma taxonomia para análise da gestão ambiental no Brasil. Revista de Administração Contemporânea, v. 8, n. 4. p. 8197.

SAATY, T.L. (1991) Método de Análise Hierárquica. São Paulo: Makron Books. 291p.

SÃO PAULO (Estado) (2011). Secretaria de Agricultura e Abastecimento Coordenadoria de Assistência Técnica Integral. Instituto de Economia Agrícola. Levantamento censitário de unidades de produção agrícola do Estado de São Paulo LUPA 2007/2008. São Paulo: SAA/CATI/IEA, 2008. Disponível em <http://www.cati.sp.gov.br/projetolupa>. Acesso em: 23 mar. 2011.

SHIMIZU, T. (2010) Decisão nas organizações. 3 ed. São Paulo: Atlas. 347p.

SISTEMA DE INFORMAÇÕES PARA O GERENCIAMENTO DE RECURSOS HIÍRICOS DO ESTADO DESÃO PAULO -SIGRH. (2O12) CBH Mogi. Disponível em: <http://www.sigrh.sp.gov.br/cgibin/sigrh_home_colegiado.exe?TEMA=APR ESENTACAO\&COLEGIADO=CRH/CBHMOGI\&lwgactw=331822>. Acesso em: 17 mar. 2012.

STORANI, D. L. \& PEREZ FILHO, A. (2009) Unidades geosistêmicas na Bacia Hidrográfica do rio Mogi Guaçu/SP. In: 130Simpósio Brasileiro de Geografia Física Aplicada. Anais... Viçosa: UFV.

UNIÃO DA INDÚSTRIA DE CANADEAÇÚCAR - UNICA. (2012) Produção brasileira de açúcar e de etanol. Disponível em: <http://www.unica.com.br/ dadosCotacao/estatistica/>. Acesso em: 07 abr. 2012. 